\title{
Arterial oxygen saturation over time and sleep studies in quadriplegic patients
}

\author{
C Cahan MD, B Gothe MD, M J Decker CRTT, J L Arnold BSEP, K P Strohl MD* \\ Department of Medicine, Case Western Reserve University, Division of Pulmonary and \\ Critical Care Medicine, University Hospitals of Cleveland, and The Cleveland Veterans \\ Administration, Cleveland, Ohio 44106, USA.
}

\begin{abstract}
This study evaluated arterial oxygen saturation $\left(\mathrm{SaO}_{2}\right)$ over time in a randomly selected group of quadriplegic patients to assess whether clinical history prospectively correlated with profiles of oxygen saturation. In 16 stable male quadriplegic patients (C4-T5), we used pulse oximetry to measure $\mathrm{SaO}_{2}$ over a 24 hour period. Measured values of $\mathrm{SaO}_{2}$ were formatted into a cumulative frequency distribution of $\mathrm{SaO}_{2}$ over time. The cumulative $\mathrm{SaO}_{2}$ values from the quadriplegic patients were compared to $\mathrm{SaO}_{2}$ values in a control group of 12 age-matched healthy male subjects. Ten quadriplegic patients had $\mathrm{SaO}_{2}$ profiles comparable to the range observed in healthy subjects. Six quadriplegic patients had $\mathrm{SaO}_{2}$ profiles outside of the normative range. These 6 exhibited cyclic desaturations $(>4 \%)$ during periods of behaviorally-defined sleep, suggestive of sleep-disordered breathing. During wakefulness, however, their values of $\mathrm{SaO}_{2}$ were within the normative range. With respect to level of injury, age, time after injury, or medication use, there was no difference between the six 'hypoxic' quadriplegic patients and the 10 'normoxic' quadriplegic patients. Five of the 6 hypoxic patients had a positive medical history of snoring and increased daytime sleepiness, as compared to 6 of 10 normoxic patients who gave a similar history. We also performed polysomnographic studies in a subgroup of 7 quadriplegic patients. In this subgroup, sleep-disordered breathing was observed in 3 patients (AHI of 54/53/12 per hour, respectively). We conclude that in quadriplegic patients, in whom there is a low clinical suspicion for sleep-disordered breathing, there can occur significant decreases in $\mathrm{SaO}_{2}$ over time.
\end{abstract}

Keywords: arterial oxygen saturation; quadriplegia; sleep apnea.

\section{Introduction}

The quadriplegic patient has inspiratory muscle weakness which limits the expansion of the chest wall, as well as a blunting of the chemical drive to breathe during wakefulness $^{1}$ and obstructive apneas during sleep. ${ }^{2}$ However, due to their intensive nursing and personal needs, it is difficult to study quadriplegic patients in specialized laboratories for sleep and breathing. Therefore, the available data on gas exchange and oxygenation in quadriplegics are primarily composed of

*Correspondence: Pulmonary Division/Department of Medicine, Case Western Reserve University, 2074 Abington Road, Cleveland, OH 44106, USA. values obtained from arterial blood samples. The major limitation to this method is that it presents only a discreet, intermittent sample of the oxygenation profile during a 24 hour period. A better profile of oxygenation is obtained by continuously measuring arterial oxygen saturation $\left(\mathrm{SaO}_{2}\right)^{3.4}$ over a 24 hour period. Hence, a portable method to quantitatively evaluate oxygenation would be useful in identifying those patients who may require more extensive diagnostic evaluation.

In this study, we used 24-hour pulse oximetry to evaluate the $\mathrm{SaO}_{2}$ profiles in 16 stable, male quadriplegic patients. We then compared these profiles to those of 12 healthy control subjects. To further define 
respiratory events during sleep in quadriplegics, polysomnographic studies were performed in a subgroup of 7 patients.

\section{Methods and materials}

Patients and normal subjects data

Continuous pulse oximetry monitoring was performed on 16 consecutive, stable, male patients, who had been admitted to the quadriplegic ward of Wade Park Veterans Administration Medical Center, Cleveland, Ohio, USA. Fifteen patients had injury between the $\mathrm{C} 4-\mathrm{T} 4$ level while one patient had a lesion at the T4-5 level. Patients were in stable condition as judged by medical history and physical examination. Twelve age-matched, healthy male volunteers served as the control group.

All participants were asked a series of questions about their sleep habits and indicated by either yes or no whether or not they had a personal history of snoring, excessive daytime sleepiness, and existing or previous lung disease. All participants in the study gave their written consent. The study was approved by the Institutional Review Board for investigational studies.

\section{Pulse oximetry recording}

To measure $\mathrm{SaO}_{2}$ over a 24 hour period, a pulse oximeter (Criticare model 501+, Waukesha, Wisconsin, USA) was modified by the manufacturer to be powered by 4 C' cell batteries. The continuous $\mathrm{SaO}_{2}$ measurements from the pulse oximeter were recorded by an analog cassette tape recorder (Medilog recorder, Ambulatory Monitoring Inc, Ardsley, New York, USA). This system has been previously validated for recording physiologic data over 24 hours. $^{3}$

Playback of the analog cassette recording was performed through an analog playback device (Research Instrumentation Inc, Beachwood, Ohio, USA) which replayed the data at a speed 100 times faster than it was recorded. Consequently, 24 hours of data could be replayed in approximately 24 minutes. The replay device provided an analog output of the $\mathrm{SaO}_{2}$ signal which was recorded on a 2-channel strip chart recorder
(Western Graphtec Linearecorder, Irving, California, USA) at a real time speed of $5 \mathrm{~mm} / \mathrm{min}$.

\section{Data analysis}

The strip recordings of $\mathrm{SaO}_{2}$ were first evaluated for total recording time. Then all data that met exclusion criteria were subtracted from the record and all further computations. Exclusion criteria consisted of data superimposed with motion artifact or any complete signal loss creating a default signal sent from the oximeter to the recorder. A default signal could result from motion artifact, low peripheral perfusion, inadequate digit pulse pressure, peripheral digit venous congestion (due to pressure generated by the pulse oximeter's finger sensor), the sensor being dislodged, or the oximeter being inadvertently turned off.

After each strip recording was evaluated for total recording time, and all artifactual data had been edited out, each subject's strip chart recording of $\mathrm{SaO}_{2}$ was digitized with an off-line X-Y digitizer (Summagraphics Inc, Fairfield, Connecticut, USA). The data were digitized into the format of $\mathrm{SaO}_{2}$ against time, as described by Slutsky and Strohl. ${ }^{4}$ This format provides a cumulative distribution of oxygen saturation values measured during the entire recording period. For each subject, this distribution was further reduced to $\mathrm{SaO}_{2}$ values at each tenth percentile of the total recording time.

\section{Sleep studies}

Out of the 16 quadriplegic patients, 7 were willing to undergo polysomnography. Polysomnographic variables monitored were EEG $\left(\mathrm{C}_{3}-\mathrm{A}_{2}\right), \mathrm{EOG}\left(\mathrm{FP}_{1}-\mathrm{FP}_{2}\right)$, and EMG $\left(\mathrm{P}_{3}-\mathrm{P}_{4}\right)$. Airflow was measured by two thermistors, one taped to a nostril and one taped to the corner of the mouth. Thoracic and abdominal respiratory movements were measured by inductance plethysmography bands (Respitrace, Ambulatory Monitoring Inc, Ardsley, New York, USA). These were positioned around the thorax and abdomen, respectively. Oxygen saturation was measured by a Criticare $501+$ pulse oximeter. All measurements were recorded on a Grass 12-channel polygraph (model 7, 
Grass Instruments, Quincy Massachusetts, USA) at a paper speed of $10 \mathrm{~mm} / \mathrm{sec}$. Sleep staging was determined using standard techniques. ${ }^{5}$ An episode of apnea was defined as an absence of airflow for at least 10 seconds duration.

\section{Statistical methods}

Values are reported as the mean \pm one standard deviation (SD). Statistical analysis of the data was performed using Student's $t$ test for non paired samples. Results were considered significant when $p<0.05$.

\section{Results}

Continuous pulse oximetry recordings were performed in 16 quadriplegic patients and 12 healthy control subjects. The total recording time in quadriplegic patients was $22.5 \pm 0.8$ hours (mean $\pm 1 \mathrm{SD}$ ). Of this, $85.3 \pm 7.2 \%$ of the data was technically acceptable. The total recording time in normals was $23.7 \pm 1.0$ hours. Of this, $93 \pm 4 \%$ of the data was technically acceptable.
Figure 1 displays $\mathrm{SaO}_{2}$ tracings from 3 subjects. These illustrate patterns of $\mathrm{SaO}_{2}$ in one healthy subject and in 2 quadriplegic patients. In the healthy subject (panel A), tracings during sleep showed little variation in $\mathrm{SaO}_{2}$ values over time. Similar patterns were obtained from 10 of the quadriplegic patients (panel B). An abnormal pattern of repetitive cyclic desaturations, arranged in clusters (saw tooth pattern), was observed during sleep in 6 quadriplegic patients (panel C).

Figure 2 graphically displays grouped values of $\mathrm{SaO}_{2}$ for healthy subjects, and for the quadriplegic patients. Values are expressed as the mean $\mathrm{SaO}_{2} \pm 1 \mathrm{~S}$.D. at each tenth percentile. This figure illustrates that, as a group, the quadriplegics spent $20 \%$ of the recorded time at $\mathrm{SaO}_{2}$ values that were lower than those of the healthy control group $(p<0.05)$.

Based on their $\mathrm{SaO}_{2}$ profiles, we found that the quadriplegic patients could be divided into two subgroups. Ten quadriplegic patients had values of $\mathrm{SaO}_{2}$ within the normative range established by the healthy group. Six quadriplegic patients had $\mathrm{SaO}_{2}$

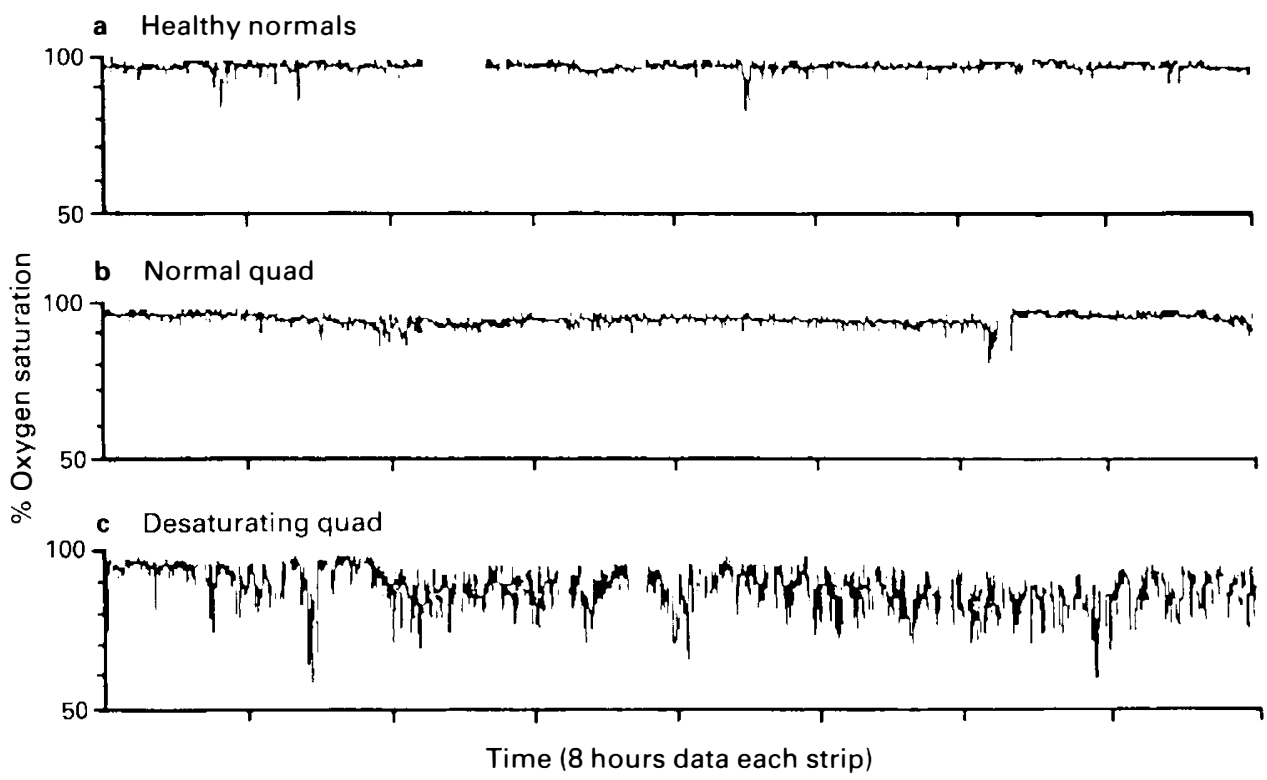

Figure 1 These are representative tracings of $\mathrm{SaO}_{2}$ from 3 subjects. In the nonsnoring healthy subjects, tracings during sleep were rather monotonic (panel A). Similar tracings were obtained from the normoxic quadriplegic patients (panel $\mathrm{B}$ ). Those quadriplegics who desaturated during sleep had repetitive cyclic desaturations $(>4 \%)$ frequently arranged in clusters (panel $C$ ). 
Values of oxygen saturation over time

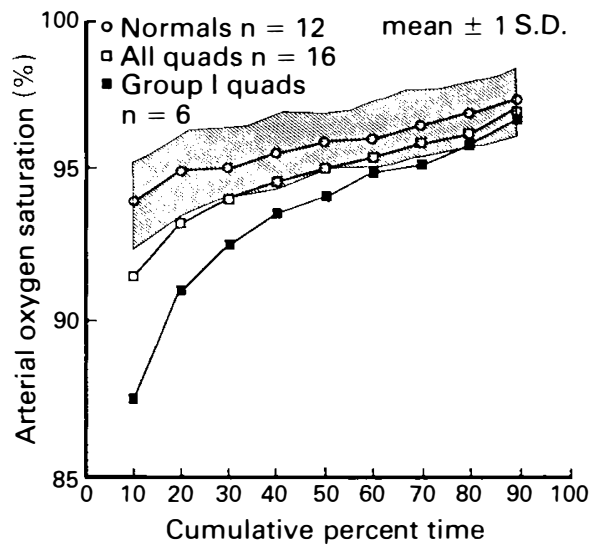

Figure 2 In this figure percent arterial oxygen saturation $\left(\mathrm{SaO}_{2}\right)$ is plotted on the ordinate and cumulative percent recording time is plotted on the abscissa. The normative range for $\mathrm{SaO}_{2}$, obtained from 12 healthy subjects is presented as hollow circles (mean) and one standard deviation of the mean (shaded area). The entire quadriplegic population (hollow squares) spent $20 \%$ of the recording time at lower $\mathrm{SaO}_{2}$ values than the healthy subjects did. Six quadriplegic patients (solid squares) showed markedly decreased $\mathrm{SaO}_{2}$ levels for up to $70 \%$ of the recording time.

profiles that fell below the normative range. These 6 spent $70 \%$ of the recorded time at an $\mathrm{SaO}_{2}$ lower than the normal range $(p<0.05)$. Specifically, these patients spent $10 \%$ of the recorded time below an $\mathrm{SaO}_{2}$ of $87.4 \%$. In all quadriplegic patients, the $\mathrm{SaO}_{2}$ values measured during behaviorally defined wakefulness was similar to the $\mathrm{SaO}_{2}$ values measured during wakefulness in the healthy subjects.

Clinical characteristics of quadriplegic patients (age, level of injury, time after injury, snoring, and symptoms of increased daytime sleepiness) are presented in Table I. In Table II the quadriplegic patients are grouped according to their $\mathrm{SaO}_{2}$ profile, either normoxic or hypoxic. The medications used by the quadriplegic patients are also listed in Table II. There was no difference between the groups with respect to their level of injury, age, time after injury, or use of medications.

Five of the 6 hypoxic quadriplegics had a medical history positive for snoring and increased daytime sleepiness as compared to 6 of the 10 normoxic quadriplegics. In Figure 3, the distribution of $\mathrm{SaO}_{2}$ values at which the symptomatic and asymptomatic quadriplegic patients spent $10 \%$ of the recorded time is compared. Mean $\mathrm{SaO}_{2}$ levels were $91.3 \pm 3.1 \%$ and $92.5 \pm 4.9 \%$ in symptomatic patients and asymptomatic patients, respectively. These were not significantly different. Hence, prediction that hypoxemia might be present could not be made by clinical history alone.

Polysomnography was performed in 7 patients who consented to a complete sleep study. Results are presented in Table III. Of these 7 patients, sleep apnea was observed in 3: apnea hypopnea index (AHI) of 54, 53 , and 12 apneas per hour, respectively. Apneas consisted of both obstructive and central events that occurred during both REM and NREM sleep.

\section{Discussion}

Several methods have been used to summarize the extent of sustained or episodic hypoxemia in patients with sleep related respiratory disorders. These include measurement of lowest $\mathrm{SaO}_{2}$ during the period of study, 6.7 averaging of minimal $\mathrm{SaO}_{2}$ values, ${ }^{7}$ sampling arterial blood gases intermittently, ${ }^{8}$ or a summary of the $\mathrm{SaO}_{2}$ profile over time. ${ }^{3.4}$ In this study we compared mean $\mathrm{SaO}_{2}$ profiles from quadriplegic patients to the mean $\mathrm{SaO}_{2}$ profile of an age-matched control group of healthy subjects. The total recording time was prolonged (23-24 hours) ensuring that saturation profiles included both wakefulness and sleep. As a group, all quadriplegics spent a significant amount of time at $\mathrm{SaO}_{2}$ levels lower than the normal range. Of the quadriplegic patients, 10 had $\mathrm{SaO}_{2}$ profiles which were within the range found in healthy subjects; however, 6 patients spent $70 \%$ of the time at $\mathrm{SaO}_{2}$ levels lower than the normative range. The latter group of patients could be at risk for hypoxic complications since they spent $>10 \%$ of the time at $\mathrm{SaO}_{2}<88 \%$. ${ }^{9}$

We found that in the quadriplegic patient hypoxemia could not be predicted by level 
Table I Clinical characteristics of quadriplegic patients

\begin{tabular}{lcccc}
\hline Patient No & $\begin{array}{c}\text { Age } \\
\text { (years) }\end{array}$ & Level of injury & $\begin{array}{c}\text { Time after injury } \\
\text { (years) }\end{array}$ & $\begin{array}{c}\text { Symptoms } \\
\text { (snoring, increased } \\
\text { sleepiness) }\end{array}$ \\
\hline Hypoxic quadriplegics & & & & \\
1 & 56 & C6 & 11 & - \\
2 & 23 & C5 -6 & 1 & + \\
3 & 55 & T3-4 & 17 & + \\
4 & 64 & C6 & 32 & + \\
5 & 56 & C6 & 13 & + \\
6 & 39 & C6 & 8 & + \\
Mean \pm S.D. & $49 \pm 15$ & & $14 \pm 10$ & + \\
Normoxic quadriplegics & & & & + \\
7 & 56 & C4-5 & 5 & + \\
8 & 78 & C5 & 19 & + \\
9 & 23 & C5-6 & 1 & + \\
10 & 55 & C6 & 20 & + \\
11 & 29 & C4 & 0.5 & + \\
12 & 21 & T4-5 & 3 & + \\
13 & 61 & C4-5 & 31 & + \\
14 & 56 & T3 & 12 & + \\
15 & 44 & C6 & 16 & + \\
16 & 60 & T3 & 30 & + \\
Mean \pm S.D. & $48 \pm 19$ & & $14 \pm 11$ & + \\
\hline
\end{tabular}

Table II Medications

\begin{tabular}{|c|c|c|c|}
\hline \multicolumn{2}{|c|}{ Muscle relaxant } & Antibiotics & Others \\
\hline \multicolumn{4}{|c|}{ Hypoxic quadriplegics } \\
\hline 1 & None & None & Furosemide, metoprolol \\
\hline & Baclophen, diazepam & Bactrim & Verapamil, oxybutynin, docusate $\mathrm{Ca}^{++}$ \\
\hline 4 & Baclophen, diazepam & Bactrim & Aspirin \\
\hline 5 & Baclophen, diazepam & Bactrim & Amitryptilin, ibuprofen \\
\hline 6 & None & None & None \\
\hline \multicolumn{4}{|c|}{ Normoxic quadriplegics } \\
\hline \multirow{2}{*}{\multicolumn{2}{|c|}{7 Diazepam }} & Methenamine & Furosemide, diphenhydramine $\mathrm{HCl}$. \\
\hline & & Mandelate & Mylanta II \\
\hline 8 & Baclophen & Bactrim & Kaopectate \\
\hline 9 & Baclophen & Bactrim & Ephedrine $\mathrm{SO}_{4}$ \\
\hline 10 & Baclophen, diazepam & Bactrim & Ephedrine $\mathrm{SO}_{4}$, metaproteronol \\
\hline 11 & Baclophen, diazepam & Bactrim & Ibuprofen, cimetidine \\
\hline 12 & Baclophen, diazepam & None & Aspirin \\
\hline 13 & None & None & None \\
\hline 14 & Diazepam & Bactrim & Ephedrin $\mathrm{SO}_{+}$, Florinef \\
\hline 15 & None & None & None \\
\hline \multirow[t]{2}{*}{16} & Diazepam & Methenamine. & Ephedrin $\mathrm{SO}_{+}$, Surfax, \\
\hline & & Mandelate & Propoxyphene. Acetaminophen \\
\hline
\end{tabular}

of injury, medications, age, or time after injury. Additionally, there was no evidence of acute respiratory illness which could explain the difference in $\mathrm{SaO}_{2}$ profiles between the two groups of quadriplegic patients. We also found that neither the hypoxemic or nonhypoxemic patients could be distinguished by historical data. Symp- 


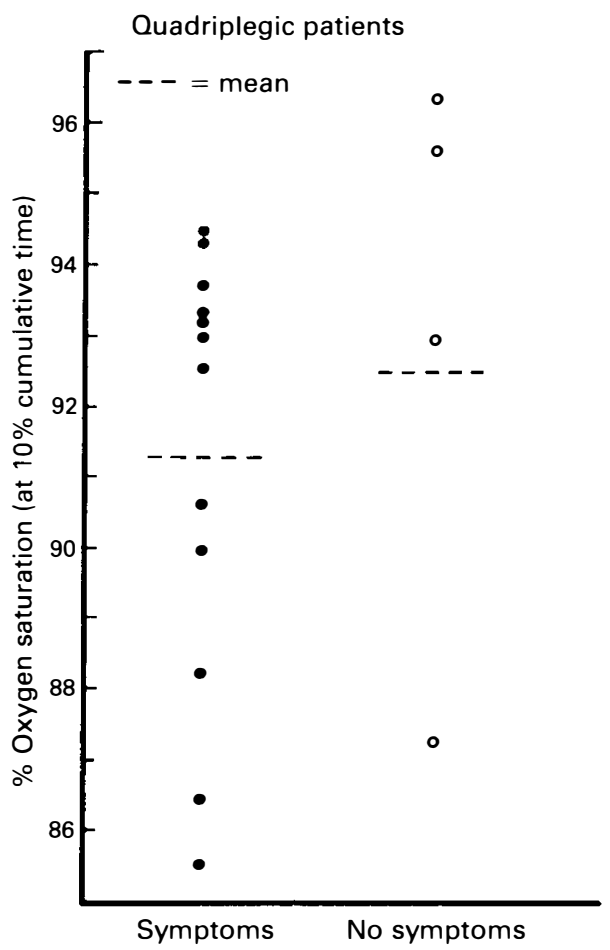

Figure 3 This figure compares the distribution of $\mathrm{SaO}_{2}$ values at $10 \%$ of the cumulative recording time for the two groups of quadriplegic patients. Those quadriplegics with a history of snoring and increased daytime sleepiness are represented by solid circles. Those quadriplegics without a history of snoring or increased daytime sleepiness are represented by the hollow circles. Mean $\mathrm{SaO}_{2}$ in both groups was not significantly different, hence prediction that hypoxemia might exist could not be made by clinical history.

toms suggestive of sleep apnea, such as snoring and increased daytime sleepiness, occurred in 6 of the 10 quadriplegics with normal $\mathrm{SaO}_{2}$ profiles and in 5 of the 6 quadriplegics with an abnormal $\mathrm{SaO}_{2}$ profile.

Continuous $\mathrm{SaO}_{2}$ monitoring allowed assessment of oxygenation during wakefulness as well as sleep and detected clinically relevant hypoxemia in a group of quadriplegic patients. There are several possible mechanisms of hypoxemia in quadriplegic patients. Loss of expiratory muscle function interferes with coughing, causing atelectasis and mismatching of ventilation and perfu- sion. Partial loss of respiratory muscle function causes small tidal volumes that promote small airway closure and thus perpetuate microatelectasis. Another factor that may play a role in hypoxemia is low functional residual capacity (FRC). If a patient has a low FRC and also experiences a fall in alveolar ventilation, there may occur a precipitous fall in $\mathrm{SaO}_{2} \cdot{ }^{10}$ Finally, decreases in $\mathrm{SaO}_{2}$ also could be related to apneic events occurring during sleep. None of these mechanisms are specifically identified by pulse oximetry alone.

Polysomography is one method that helps to distinguish between the several mechanisms which may be responsible for hypoxemia; in addition it also provides information on sleep architecture. One previous study of 4 patients with spinal cord injury used polysomnography to document sleep apnea in those patients who were referred for evaluation of possible sleep-disordered breathing. ${ }^{2}$ The polysomnographic studies we performed were on symptomatic and asymptomatic patients. We found that in regard to sleep architecture, the sleep pattern in the quadriplegic is disrupted with more arousals than normal. Sleep onset was variable and patients spent a significant time of the study awake, and at stage I sleep. Less time was spent in stage II sleep and REM sleep was significantly decreased. Furthermore, an apnea/hypopnea index diagnostic for sleep apnea was present in only 3 of the 7 patients. Similar findings of a range of sleep arousals and apneas are reported in patients with interstitial lung disease $^{11,12}$ or neuromuscular disorders. ${ }^{13-15}$

We believe that clinically unexpected sleep apnea can be inferred from pulse oximetry measurements of $\mathrm{SaO}_{2}$ during sleep. We found that during sleep the quadriplegics who were hypoxic had repetitive desaturations frequently arranged in clusters. The descending limb of the desaturation was gradual but the ascending limb (the reoxygenation) was abrupt. This provided the waveform with a 'saw tooth' type pattern which is reported in obstructive sleep apnea. ${ }^{16,17}$ These patterns are distinctly different from patterns of $\mathrm{SaO}_{2}$ seen in normal subjects or in the normoxic quadriplegics. 
Table III Sleep studies

\begin{tabular}{|c|c|c|c|c|c|c|c|c|c|c|}
\hline $\begin{array}{l}\text { Length } \\
\text { of study } \\
\text { (min) }\end{array}$ & $\begin{array}{l}\text { Sleep } \\
\text { onset } \\
\text { (min) }\end{array}$ & $\begin{array}{l}\text { REM } \\
\text { latency } \\
(\mathrm{min})\end{array}$ & $\begin{array}{c}\text { I } \\
(\%) \\
*\end{array}$ & $\begin{array}{c}\text { II } \\
(\%) \\
*\end{array}$ & $\begin{array}{c}\text { REM } \\
(\%) \\
*\end{array}$ & $\begin{array}{c}\text { Awake } \\
(\%) \\
*\end{array}$ & $\begin{array}{l}\text { Apnea/ } \\
\text { hyponea } \\
\text { index }\end{array}$ & $\begin{array}{l}\text { Apnea hyp } \\
\text { events/h } \\
\text { NonREM }\end{array}$ & $\begin{array}{l}\text { poneas } \\
\text { hour } \\
\text { REM }\end{array}$ & $\begin{array}{l}\text { Symptoms } \\
\text { ie sleepiness } \\
\text { snoring }\end{array}$ \\
\hline 174 & 90 & NO & 20 & 14 & 0 & 66 & $<5$ & & & - \\
\hline 290 & 31 & NO & 27 & 9 & 0 & 4 & $<5$ & & & + \\
\hline 170 & 22 & 110 & 60 & 17 & 7 & 16 & 54 & 100 & 0 & + \\
\hline 245 & 57 & 150 & 36 & 18 & 5 & 41 & 12 & 88 & 12 & + \\
\hline 197 & 1 & 23 & 7 & 57 & 10 & 26 & $<5$ & & & + \\
\hline 225 & 17 & 102 & 17 & 62 & 10 & 11 & $<5$ & & & + \\
\hline 221 & 1 & 172 & 17 & 23 & 7 & 56 & 53 & 96 & 4 & + \\
\hline \multicolumn{11}{|c|}{ Mean \pm 1 SD } \\
\hline 217 & 31 & 94 & 26 & 27 & 5 & 41 & & & & \\
\hline \pm & \pm & \pm & \pm & \pm & \pm & \pm & & & & \\
\hline 42 & 32 & 68 & 17 & 8 & 3 & 24 & & & & \\
\hline
\end{tabular}

*These values are derived by the following equation: total sleep time equals the time from sleep onset (second column) to the end of the study, ie length of study - sleep onset $=$ total sleep time (in minutes). The columns labelled I (\%), II (\%), REM (\%), and Awake (\%), show a percentage of the total sleep time. NO: Not observed. These patients had no REM sleep.

Quadriplegic patients have several reasons to have a predisposition for sleep apnea and hypoventilation during sleep. One is related to increased upper airway resistance which may be exacerbated during sleep, especially in the supine posture. Lack of coordination between respiratory muscles, resulting in an imbalance between airway dilator muscles and thoracic muscles, may also account for obstructive apneas of hypopneas in quadriplegic patients. However, data on upper airway resistance in quadriplegic patients is not available. Also, quadriplegic patients have decreased lung volumes and it has been reported that there can be a reduction in pharyngeal cross sectional area with decreasing lung volumes. $^{18}$

Sleep-disordered breathing may also occur secondary to abnormal ventilatory responsiveness. Unlike patients with intrapulmonary restriction who have stimulation of pulmonary vagal receptors with resultant hyperventilation, quadriplegics are known to have impaired responses to $\mathrm{CO}_{2}$ and, depending on the severity of the respiratory muscle involvement, may have chronic hypercapnia. ${ }^{1.19}$ Furthermore, quadriplegic patients differ from normal subjects in their response to both elastic and resistive loading. ${ }^{20}$ These differences could promote hypoventilation and hypoxemia during wakefulness or sleep.

We demonstrate that in clinically stable quadriplegic patients there can occur significant decreases in $\mathrm{SaO}_{2}$ over time as measured by pulse oximetry. This can be attributed in some cases to clinically significant sleep apnea. Our conclusion is that the quadriplegic patients who are hypoxic during sleep are better identified by monitoring $\mathrm{SaO}_{2}$ or sleep studies, rather than by the clinical history.

\section{Acknowledgement}

Dr Strohl is the recipient of a Research Career Development Award from the National Institutes of Health (HL-02011). We thank J Leitner for technical assistance in performance of the sleep studies. This work is supported in part by a Specialized Center in Cardiopulmonary Disorders of Sleep (SCOR) HL-42215 and by HL-25830.

\section{References}

1 Bergofsky EH (1964) Mechanisms for respiratory insufficiency after cervical cord injury. Ann Intern Med 61: 435-447. 
2 Bonekat HW, Andersen G, Squires J (1990) Obstructive disordered breathing during sleep in patients with spinal cord injury. Paraplegia 28: 392-398.

3 Decker MJ, Hoekje PL, Strohl KP (1989) Ambulatory monitoring of arterial oxygen saturation. Chest 95: 717-722.

4 Slutsky AS, Strohl KP (1980) Quantification of oxygenation during episodic hypoxemia. Am Rev Respir Dis 121: 893-895.

5 Rechtschaffen A, Kales A (1968) A manual of standardized terminology, techniques and scoring system for sleep stages for human subjects. National Institute of Health publication number 204. Department of Health and Human Services, Washington.

6 Wynne JW, Block AJ, Hemenway J, Hunt LA, Flick MR (1979) Disordered breathing and oxygen desaturation during sleep in patients with chronic obstructive lung disease (COLD). Am J Med 66: 573-579.

7 Block AJ, Boysen PG, Wynne JW, Hunt LA (1979) Sleep apnea, hypopnea, and oxygen desaturation in normal subjects. $N$ Engl J Med 300: 513-517.

8 Orr WC, Imes NK, Martin RJ (1979) Progesterone therapy in obese patients with sleep apnea. Arch Intern Med 139: 109-111.

9 Conference Report (1988) Further recommendations for prescribing and supplying long term oxygen therapy. Am Rev Respir Dis 138: 745-747.

10 Shepard JW (1985) Gas exchange and hemodynamics during sleep. Med Clin North Am 69: 1243-1252.

11 Bye PT, Issa F, Berthon-Jones M. Sullivan CE (1984) Studies of oxygenation during sleep in patients with interstitial lung disease. Am Rev Respir Dis 129: 27.

12 Perez-Padilla R, West P, Lerzman M, Kryger MH (1985) Breathing during sleep in patients with interstitial lung disease. Am Rev Respir Dis 132: 224-229.

13 Newsom Davis J, Goldman M, Loh L, Casson M (1976) Diaphragm function and alveolar hypoventilation. $Q J$ Med 45(177): 87-100.

14 Kilburn KH, Eagan JT, Sieker HO, Heyman A (1959) Cardiopulmonary insufficiency in myotonic and progressive muscular dystrophy. $N$ Engl J Med 126(22): 1089-1096.

15 Cumminsky J, Lynne Davies P. Guillenimaut C (1978) Sleep studies and respiratory muscle function in muscular dystrophy. In Guillenimaut C, Dement W. editors. Sleep Apnea Syndromes. Allen R Liss, New York: 295-308.

16 Goldman MD, Casey KR (1988) Pattern of cyclic oxygen de- and re-saturation predicts central vs obstructive sleep apnea at 1400 altitude. The Phy'siologist 31: 4.

17 Evans RJ, Wilhoit SC, Suratt PM (1984) A microcomputer system for monitoring and analyzing oxyhemoglobin saturation during sleep. Computer Programs in Biomedicine 18: 227-234.

18 Hoffstein V, Zamel N, Phillipson EA (1984) Lung volume dependence of pharyngeal cross-sectional area in patients with obstructive sleep apnoea. Am Rev Respir Dis 130: 175-78.

19 Killing JS, DiMarco AF, Gottfried SB, Altose MD (1985) Respiratory responses to ventilatory loading following low cervical spinal cord injury. J Appl Physiol 59: 1752-1756.

20 Axen K (1984) Adaptations of quadriplegic men to consecutively loaded breaths. J Appl Physiol 56: 1099-1103. 